\title{
PARTICULATE MATTER ASSESSMENT IN THE AIR BASED ON THE HEAVY METALS PRESENCE
}

\author{
Dušan JANDAČKA ${ }^{1, *}$, Daniela ĎURČANSKÁ ${ }^{1}$ \\ ${ }^{1}$ Department of Highway Engineering, Faculty of Civil Engineering, University of Žilina, Žilina, \\ Slovakia. \\ corresponding author: dusan.jandacka@fstav.uniza.sk, +421-41-5135948.
}

\begin{abstract}
Particulate matters are the result of various processes in the atmosphere that are part of everyday life. The chemical composition of these particles is mainly influenced by their origin. Their behavior is also dependent on meteorological conditions and other factors as well. The aim of this paper was to identify sources of particulate matters by means of statistical methods due to the presence of 17 heavy metals. The problem solving assumes the knowledge of multivariate statistical data analysis methods as principal components analysis (PCA), factor analysis (FA) and multivariate regression and vector algebra. For the application of methodology suitable software may prove appropriate.
\end{abstract}

\author{
Keywords: \\ Air pollution; \\ Heavy metals; \\ Particulate matter; \\ $\mathrm{PM}_{10}$; \\ Road traffic; \\ Statistical methods.
}

\section{Introduction}

Emissions from different sources create a very complex mixture in the air both in qualitative and quantitative terms. Their composition is the result of distribution of all the sources in space and time, their size and characteristics of the pollutants on one side, and meteorological and climatic conditions on the other.

Heavy metals belong among the most basic groups of contaminants which are monitored in the various parts of the environment. The concerned group of contaminants is quite a large one, including the contaminants having a variable source of their origination and in many cases, the contaminants concerned share a different platform of professional approach from the scientific circles related to their impact and influence as related to the health of population.

The subject of monitoring, pursuant to the general law [1] are the following elements: As, Cd, $\mathrm{Hg}, \mathrm{Pb}$ and $\mathrm{Ni}$. These are generally considered as the most harmful to people and animals. Their limits are governed by the Public Notice [2]. Even some of the other elements may be of dangerous nature, which is to be found in soils where they are necessary in small amounts; however, when accumulated in large quantities, they may have an even more toxic impact than the aforementioned elements. In this way, the following elements are to be considered: $\mathrm{Cr}, \mathrm{Co}, \mathrm{Sn}, \mathrm{Sb}, \mathrm{Cu}, \mathrm{Ni}, \mathrm{Ag}, \mathrm{Au}, \mathrm{Zn}, \mathrm{Mo}, \mathrm{V}$, $\mathrm{Mn}, \mathrm{Fe}$ and other [3]. These elements are bound with fine particles of aerosols. Heavy metals do enter the environment by virtue of natural and anthropogenic processes. Natural sources include in situ weathering processes and atmospheric deposition of metals, oceanic processes and volcanic eruptions. Anthropogenic sources include burning fossil fuels in order to generate electricity, raw materials excavation and ore processing, industrial processes, agricultural activities and a continuously increased usage of motor vehicles.

\section{Methodology to determine the amounts of PM and chemical analysis of PM}

Readings of particulate matter were performed in the close vicinity of the urban connecting route, road in regular intervals, namely 4 times per year (years $2010-2013$ ). The goal was a longterm monitoring of a proportional representation of particulate matter (PM) in the atmosphere and its behaviour when related to the outer conditions. In the second phase of project a chemical analysis of particulate matter was performed as well as the determination of its possible source. 
In order to establish the amount of particulate matter present in the outer atmosphere, a reference method pursuant to the standards of STN EN 12341 [4] and STN EN 14907 [5] was used. The measurement readings were performed by means of low volume flow samplers of LECKEL LVS3 (Single Filter Gravimetric Sampler) amounting to the total number of 3 pieces. Concurrently, the three fractions of particulate matter were monitored, which include the following: $\mathrm{PM}_{10}, \mathrm{PM}_{2.5}$ and $\mathrm{PM}_{1.0}$. They were trapped in nitrocellulose filters of the $47 \mathrm{~mm}$ diameter and assessed in a gravimetric manner. The monitoring of atmosphere along the concerned road, route was performed in weekly cycles.

Alongside monitoring the PM there were basic meteorological data observed, as well: temperature, ambient humidity, speed and direction of wind, precipitation. The monitoring station was situated in the Zilina city centre, in the Vojtech Spanyola Street. The street as such represents one of the arteries encompassing the secondary and tertiary city ring roads, which connect the city centre with the largest housing estate of - Vlčince. This is reflected in the high traffic volume. The adjacent buildings along the road are represented by the housing developments and the civil amenities and facilities. Pavements for the pedestrians copy both sides of the monitored road. The monitoring devices were situated in the close vicinity of the boundary of pavement.

The particulate matter is bound with various elements and compounds. In the second phase did we concentrate on the monitoring of the selected heavy metals found in the fraction of $\mathrm{PM}_{10}$. We focused on monitoring 17 metals which we selected based on the assumptions and probabilities following their origination in the vehicular traffic. Each of these metals may come from a specific source (Table 1). Based on a sufficiently comprehensive database of data it deems possible by the utilization of multidimensional statistical methods (for instance factor analysis), to more closely specify the possible source of these particles.

In order to identify or to determine the present chemical form of an observed element in the sample of particulate matter the spectroscopic methods are utilized. The analyses of filters and the determination of metals present in the fraction of $\mathrm{PM}_{10}$ were performed pursuant to the standard of STN EN 14902 [6].

Table 1: Sources of metals contained in the particulate matter - in general $[7,8,9,10,11,12]$.

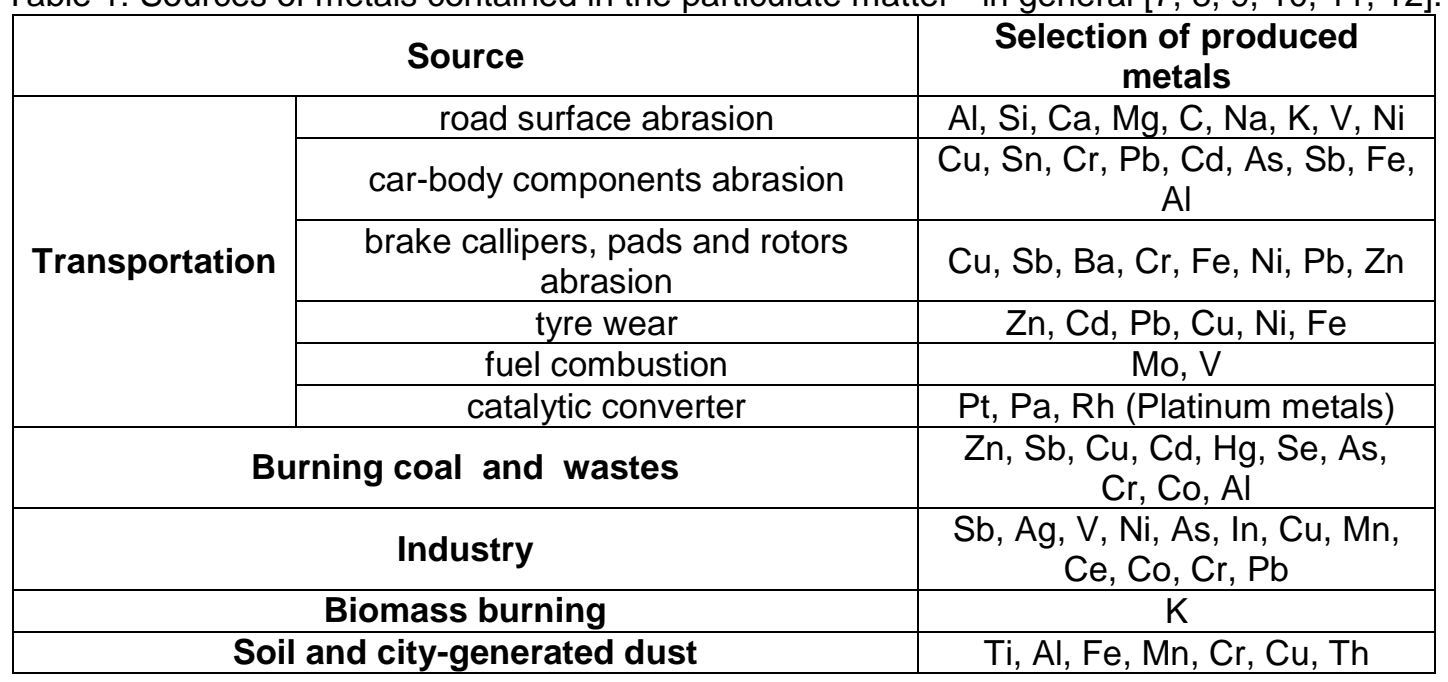

Prior to specifying inorganic pollutants, the filters were reacted by the mixture of acids $\left(\mathrm{HNO}_{3}\right.$ and $\mathrm{HF}$ ) and oxidizing agents with a resultant specification by means of the mass spectrometry method with inductively coupled plasma mass spectrometer ICP MS (Perkin - Elmer ELAN 6000 - USA) in cooperation with the Institute of Geology at the Faculty of Natural Sciences of Comenius University in Bratislava [13]. 


\section{Assessment methodology and adopted statistical methods}

\subsection{Statistical assessment of results in the PM monitoring}

Quantitative distribution of PM taking into account the monitoring period (seasonal periods) during the course of sampling between the years of 2010 and 2013 differed. It is, predominantly, referred to the presence of fine fraction within the overall fraction of $\mathrm{PM}_{10}$. During the course of October 2010, the fine fraction of $\mathrm{PM}_{2,5}$ being present in the $\mathrm{PM}_{10}$ on average amounting to $69 \%$, during the course of March 2011 amounting to $70 \%$, during the course of April 2011 amounting to $65 \%$, during the course of July 2011 amounting to $68 \%$, during the course of October 2011 amounting to $66 \%$, during the course of January 2012 amounting to $90 \%$ (too low temperatures recorded and an inversion, as well), during the course of April 2012 amounting to $83 \%$ and during the course of June 2012 amounting to $77 \%$. The highest concentrations of PM were recorded during the monitoring period of January 2012. $\mathrm{PM}_{10}$ fraction reached the highest concentrations possible as of the 24-hour sampling cycles, resulting in $158.54 \mu \mathrm{g} / \mathrm{m}^{3}$ which occurred on the day of 29.01 .2012 and $\mathrm{PM}_{2,5}$ fraction resulting in $148.95 \mu \mathrm{g} / \mathrm{m}^{3}$ which occurred on the day of 29.01 .2012 (Fig. 1) (Mean temperature as of a given day reached $-7.93^{\circ} \mathrm{C}$ ) [14].

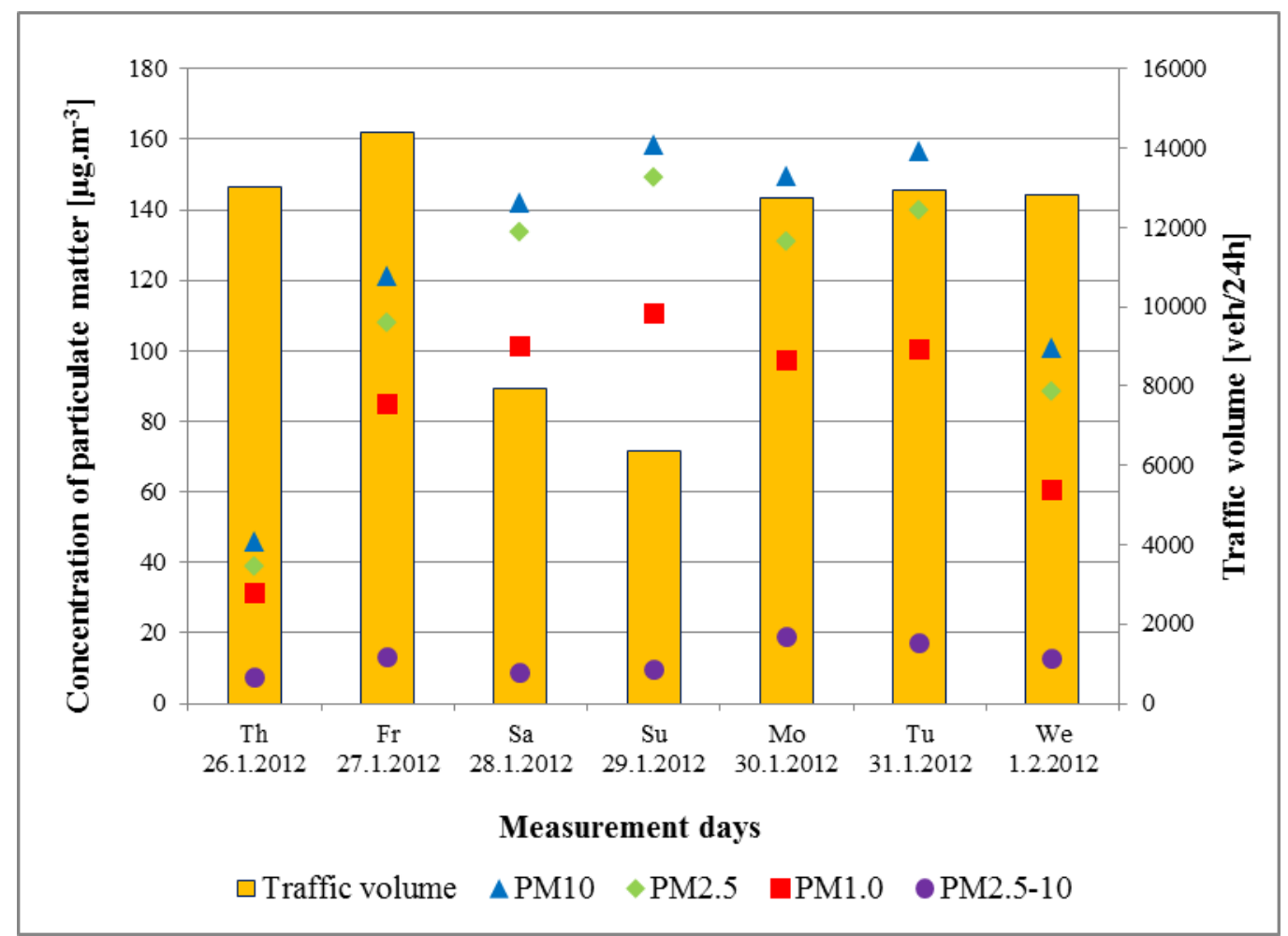

Fig.1: Concentrations PM and traffic volume during measuring period January 2012.

The statistical analysis was performed by means of the STATISTICA programme. The analysis of changes in PM concentrations in the ambient air was focused on the determination of significant independent variables which impact on the selected PM fractions. Multivariate linear regression analysis /the regression equation/ was adopted.

Multi-linear regression analysis - MRA concerns the group of techniques serving the purpose of study in the field of linear dependency between the two or more variables. Whereas the estimates of $\beta$ parameters are defined in the regression model:

$$
y_{i}=\beta_{0}+\beta_{1} \times x_{i, 1}+\beta_{2} \times x_{i, 2}+\ldots+\beta_{m} \times x_{i, m}+\varepsilon_{i} .
$$


Where $x$ are independent variables and $y$ is to be views as a dependant variable. The index of $i$ defines the serial number of monitoring and $\beta$ are to be understood as regression parameters and $b$ their estimates amounting to the overall number of $m$. $\varepsilon_{i}$ is error (residue) of $i$-th measurement. An absolute member of $\beta_{0}$ is an intersection of regression hyperplane with the $y$ axis. The estimates of $b_{i}$ are to be understood as the directions of the regression hyperplane from the direction of $x_{j}$ and are called parcial regression parameters (eventaully partial regression coeficients for the standardised variables) [15].

As the dependent variables they had been entering the model of the following fractions: $\mathrm{PM}_{10}$, $\mathrm{PM}_{2.5-10}, \mathrm{PM}_{2.5}, \mathrm{PM}_{1.0}\left[\mathrm{\mu g} / \mathrm{m}^{3}\right]$. Diverse behaviour of particulate matter was observed as far as their sizes were concerned, that is why the fractions of $\mathrm{PM}_{10}$ - the overall monitored fraction, $\mathrm{PM}_{2.5-10}-$ coarse fraction, $\mathrm{PM}_{2.5}$ - fine fraction and $\mathrm{PM}_{1.0}$ - very fine fraction were selected.

As the independent variables there were meteorological parameters selected (ambient air temperature $\left[{ }^{\circ} \mathrm{C}\right]$, ambient air humidity [\%], precipitation total $[\mathrm{mm} / 24 \mathrm{~h}]$, speed of wind $[\mathrm{m} / \mathrm{s}]$ ) and vehicular load, intensity [vehicles/24h]. Meteorological data of temperature, humidity, speed of wind were averaged as of 24 hours and the precipitation represented the total of 24 hours.

Table 2: Part of the data matrix observed variables: PM concentrations, meteorological conditions and the traffic volume [14].

\begin{tabular}{|l|c|c|c|c|c|c|c|c|c|c|}
\hline & $\mathbf{P M}_{\mathbf{1 . 0}}$ & $\mathbf{P M}_{\mathbf{1 - 2 . 5}}$ & $\mathbf{P M}_{\mathbf{2 . 5}}$ & $\mathbf{P M}_{\mathbf{2}, \mathbf{5}-\mathbf{1 0}}$ & $\mathbf{P M}_{\mathbf{1 0}}$ & Temperature & $\begin{array}{c}\text { Air } \\
\text { humidity }\end{array}$ & Rainfall & $\begin{array}{c}\text { Wind } \\
\text { speed }\end{array}$ & $\begin{array}{c}\text { Traffic } \\
\text { volume }\end{array}$ \\
\hline $\mathbf{1}$ & 43.34 & 3.73 & 47.07 & 4.13 & 51.21 & 6.00 & 87.40 & 0.10 & 0.85 & 12595 \\
\hline $\mathbf{2}$ & 23.58 & 10.84 & 34.41 & 12.65 & 47.06 & 7.01 & 76.10 & 1.80 & 0.08 & 13402 \\
\hline $\mathbf{3}$ & 25.49 & 1.73 & 27.22 & 5.14 & 32.36 & 6.66 & 79.10 & 0.30 & 0.10 & 13706 \\
\hline $\mathbf{4}$ & 47.64 & 0.00 & 44.76 & 35.70 & 80.46 & 6.49 & 75.60 & 0.30 & 0.66 & 15434 \\
\hline $\mathbf{5}$ & 42.15 & 2.75 & 44.90 & 21.14 & 66.04 & 4.57 & 62.50 & 0.00 & 0.76 & 10056 \\
\hline $\mathbf{:} \cdot$ & $\vdots$ & $\vdots$ & $\vdots$ & $\vdots$ & $\vdots$ & $\vdots$ & $\vdots$ & $\vdots$ & $\vdots$ & $\vdots$ \\
\hline $\mathbf{5 4}$ & 13.35 & 9.08 & 22.43 & 7.93 & 30.36 & 15.69 & 80.30 & 1.47 & 0.01 & 13439 \\
\hline $\mathbf{5 5}$ & 14.78 & 3.14 & 17.92 & 5.95 & 23.87 & 15.89 & 85.20 & 14.78 & 0.05 & 13064 \\
\hline $\mathbf{5 6}$ & 9.75 & 9.94 & 19.69 & 0.00 & 17.76 & 14.07 & 89.80 & 20.19 & 0.12 & 13342 \\
\hline
\end{tabular}

The data entering the model are quoted within the chart (Table 2) - five independent variables, 5 dependent variables - PM (for a given model there was always only one variable choses) and 56 entities.

In order to eliminate insignificant variables within the model and in order to compile the model consisting of entirely significant variables, there was a multivariate linear regression performed stepwise, forward selection. of $\mathrm{PM}_{1.0}$.

Here we are to quote the results of the multivariate linear regression for the dependent variable

Table 3: Significant variables for a dependent variable of $\mathrm{PM}_{1.0}$ and selected characteristics [14].

\begin{tabular}{|c|c|c|}
\hline Variable & Parameter, $\boldsymbol{b}^{\boldsymbol{\alpha}}$ & Significance, $\boldsymbol{p}^{\boldsymbol{\alpha}}$ \\
\hline Absolute term & 102.99 & 0.000000 \\
\hline Temperature & -1.90 & 0.000000 \\
\hline Air humidity & -0.67 & 0.000799 \\
\hline Wind speed & -8.58 & 0.003205 \\
\hline
\end{tabular}

The overall model is statistically speaking significant $p=0.000000$. 
Table 4: Correlation matrix for dependent variable $\mathrm{PM}_{1.0}[14]$.

\begin{tabular}{|c|c|c|c|c|c|c|}
\hline Variable & Temperature & $\begin{array}{c}\text { Air } \\
\text { humidity }\end{array}$ & Rainfall & $\begin{array}{c}\text { Wind } \\
\text { speed }\end{array}$ & $\begin{array}{c}\text { Traffic } \\
\text { volume }\end{array}$ & $\mathbf{P M}_{\mathbf{1}}$ \\
\hline Temperature & 1.000000 & -0.122017 & 0.259317 & 0.061699 & -0.024496 & $\mathbf{- 0 . 6 8 8 9 3 5}$ \\
\hline Air humidity & -0.122017 & 1.000000 & 0.372557 & -0.125306 & 0.072968 & $-\mathbf{0 . 1 8 8 8 4 6}$ \\
\hline Rainfall & 0.259317 & 0.372557 & 1.000000 & -0.081530 & 0.087678 & -0.329196 \\
\hline Wind speed & 0.061699 & -0.125306 & -0.081530 & 1.000000 & -0.039209 & $\mathbf{- 0 . 2 7 1 7 0 5}$ \\
\hline $\begin{array}{c}\text { Traffic } \\
\text { volume }\end{array}$ & -0.024496 & 0.072968 & 0.087678 & -0.039209 & 1.000000 & -0.101307 \\
\hline $\mathbf{P M}_{\mathbf{1}}$ & $\mathbf{- 0 . 6 8 8 9 3 5}$ & $\mathbf{- 0 . 1 8 8 8 4 6}$ & -0.329196 & $\mathbf{- 0 . 2 7 1 7 0 5}$ & -0.101307 & 1.000000 \\
\hline
\end{tabular}

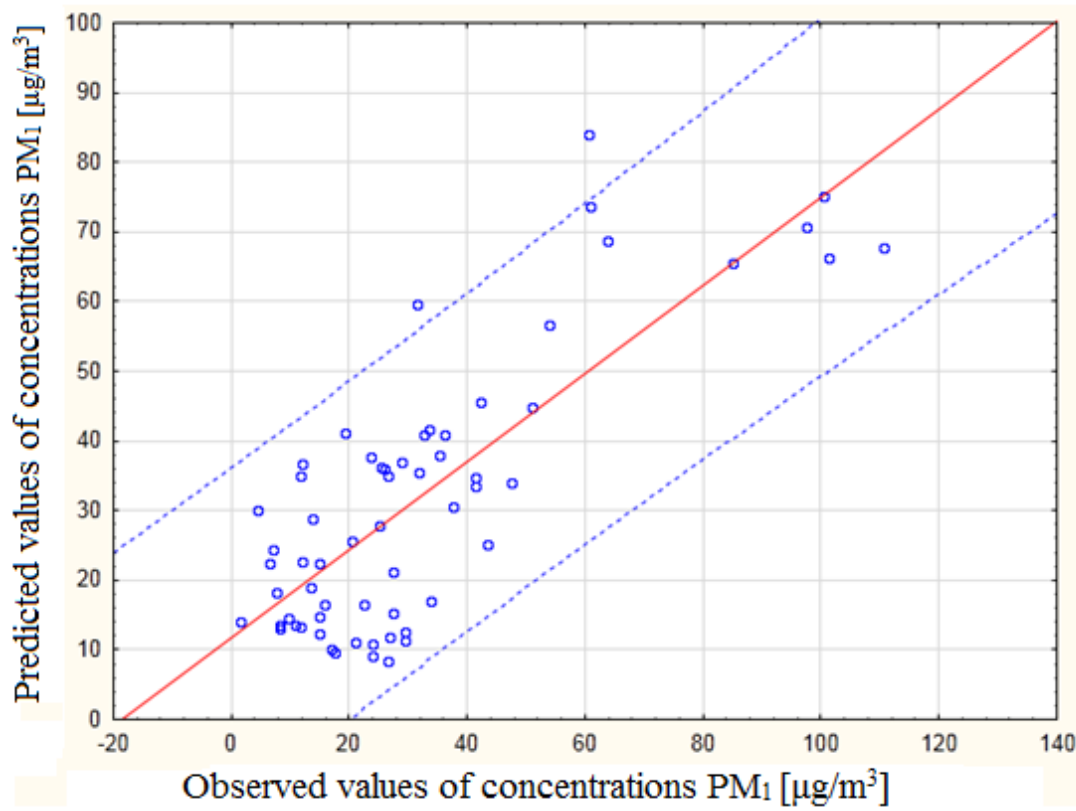

Fig. 2: Observed vs. predicted values, dependent variable $\mathrm{PM}_{1.0}$, coefficient of determination $\mathrm{R}^{2}=0.60$ [14].

PM1 vs. temperature

Temperature $=17.974-0.2737 * \mathrm{PM} 1$

Correlation: $\mathrm{r}=-0.7$
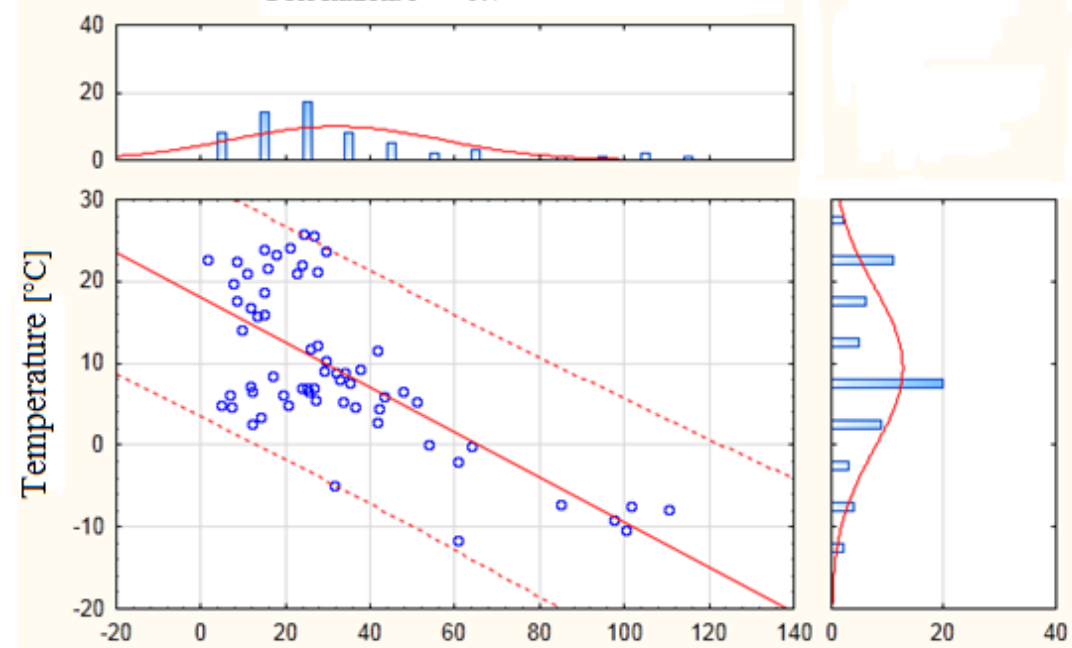

Observed values of concentrations $\mathrm{PM}_{1}\left[\mu \mathrm{g} / \mathrm{m}^{3}\right]$

Fig. 3: Partial correlation between temperature and a dependent variable $\mathrm{PM}_{1.0}$ [14]. 
Referring to a very fine fraction of $\mathrm{PM}_{1}$, the results to be understood as significant ones are the following variables: temperature, ambient air humidity, speed of wind (Table 3 ). These variables account for a negative correlation incorporating $\mathrm{PM}_{1}$ (Table 4). The model explains $60 \%$ of former data dispersion (Fig. 2). The greatest partial correlation resulted between the $\mathrm{PM}_{1}$ and temperature, having the value of correlation coefficient of -0.7 (Fig. 3).

The overall fraction of $\mathrm{PM}_{10}$, not inclusive of the fine and coarse fractions, is similarly as the fine fraction defined by equally important variables and that be the temperature, ambient air humidity and the speed of wind. The model is in this case defined by a $65 \%$ of a former dispersion of data. In order to be able to make the model more precise and accurate, the extension of the number of formerly monitored data would help for specific variables, of which the models were compiled.

By virtue of this methodology all the PM fractions were interpreted and evaluated. If we are to compare correlation matrices of statistical interpretation and assessment, we may see the one and only positive correlation coefficient between the vehicular load and particulate matter, particulates, which is to be observed with the coarse fraction of $\mathrm{PM}_{2.5-10}$. In case of all the meteorological conditions we are to deal entirely with negative correlation coefficients in all the fractions of PM - i. e. when reducing the temperature the PM concentrations are on an increase in the ambient air, whereas when reducing the ambient air humidity the concentrations of PM are on an increase.

The vehicular load and traffic intensity partially impact on the creation of the coarse fraction of the particulates. The road traffic as a significant source of particulate matter happens to be the originator of the afore mentioned, however the meteorological conditions are impaction on their concentrations in the ambient air to such an extent that it is impossible to be determining the impact of the road traffic purely based on the changes in its intensity [14].

\section{Statistical assessment of results concerning the $\mathrm{PM}_{10}$ chemical analyses}

Multivariate statistical analyses of PCA - Principal component analysis and FA - Factor analysis were used for statistical assessment.

The primary goal of PCA is the transformation of the original characters of $x_{j}, j=1, \ldots, m$, into a smaller amount of latent variables $y_{j}$. These latent variables possess more appropriate and comprehensive properties: their presence is less significant, they capture and represent almost the entire variability of the original characteristics, properties and they are mutually uncorrelated. Latent variables are known as the main components and they represent linear combinations of former variables: the first principal component (PC) $y_{1}$ describes the greatest part of variability, hence the dissipation, spread of the original data, the second principal component $y_{2}$ on the other hand the greatest part of variability, spread not-contained within $y_{1}$ etc.. Mathematically speaking, the first $P C$ is viewed as a linear combination of input characters which covers the greatest variability, spread among the other linear combinations. The disparity between the coordinates of object in the former characters and the principal components, thence the loss of information by the projection into the smaller number of dimensions is known as the fitness rate of PCA model interpretation or it is also called the PCA model error. For the first PC the following relation prevails:

$$
y_{1}=\sum_{j=1}^{m} v_{1 j} \times x_{j},
$$

where: $x_{j} \quad$ former character, input variable, $\mathrm{j}=1, \ldots, \mathrm{m}$,

$v_{1 j} \quad$ coefficients of eigenvectors.

Within the process of factor analysis (FA) so called factor loadings are estimated for particular variables (pollutants) for a generated factor. Factor loadings are the expression of correlations between the particular variables and acquired factors. Based on the values of factor loadings it is possible to specify a group of variables for each factor, those ones which correlate with it in the closest-possible manner. And vice versa, by means of factor loadings, the identified factor is appended with an extent of impact on each of particular variables. The variables with the highest factor loadings for a generated factor are considered as decisive even when interpreting such a factor. A data matrix serves the purpose of input for calculations, whose lines correlate with particular 
measurements (objects) and bars of variables, i. e. measured pollutant (character). The variables to be used are those pollutants which are able to specify anticipated sources of pollution.

The basic principle of factor analysis lies in the fact that each of monitored values $X_{j}(j=1, \ldots$, p) may be expressed as a sum of a linear combination of a lesser amount $m$ non-observed (hypothetical) random values $F_{1}, \ldots, F_{m}$-so called common factors and the further source of variability $E_{j}(j=1, \ldots, p)-$ so called specific (residual) elements. Let us suppose that the following model prevails:

$$
X_{j}=\sum_{k=1}^{m} \lambda_{j k} \times F_{k}+E_{j}
$$

where: $\lambda_{\mathrm{jk}}$ factor loadings of the $k$ common factor relevant to the $j$ variable and of $k$ factor, $\mathrm{k}=1$,

$\mathrm{F}_{\mathrm{k}} \quad \ldots, \mathrm{m}, \mathrm{k}$-th common factor,

$\mathrm{E}_{\mathrm{j}}$ is a random deviation of the exact model, relevant to the $k$-th value,

$j=1, \ldots, p$.

Values $X_{1}, \ldots, X_{p}$ are standardized, i. e. they have a zero main value and unit variance. In the matrix form we get the FA model of the following string:

$\mathbf{X}=\mathbf{\Lambda} \times \mathbf{F}+\mathbf{E}$.

The $F$ matrix is called factor matrix. Furthermore, let us suppose that the random vectors $F$ and $E$ are non-correlated. In the FA method it is recommended to have at least 5 samples, while the optimum number of samples could reach 20 per each variable. The appropriateness of factor analysis used is proven by the test of KMO (Kaiser-Meyer-Olkin) and MSA - the extent of internal correlation [16].

In order to approximate the contribution of specific sources of PM the method of Absolute Principal Component Scores is adopted, abbreviated as - APCS in conjunction with Multiple Regression Analysis - MRA. First of all the values of factor scores are estimated. In our case the weighted least squares method of Bartlett was used, which is based on the minimization of the mathematical expression:

$$
(X-\Lambda \times F)^{\prime} \times \Psi^{-1} \times(X-\Lambda \times F),
$$

where:

$$
\Psi=\operatorname{var}(E), X=\left(\begin{array}{l}
X_{1} \\
\cdot \\
\cdot \\
\cdot \\
X_{P}
\end{array}\right), \Lambda=\left(\begin{array}{ccc}
\lambda_{11} & \ldots & \lambda_{1 m} \\
\ldots & \ldots & \ldots \\
\lambda_{p 1} & \ldots & \lambda_{p m}
\end{array}\right), F=\left(\begin{array}{l}
F_{1} \\
\cdot \\
\cdot \\
\cdot \\
F_{m}
\end{array}\right), E=\left(\begin{array}{l}
E_{1} \\
\cdot \\
\cdot \\
\cdot \\
E_{P}
\end{array}\right) \text {, }
$$

Taking into account the fact of an unknown $F$ factor, bearing in mind that instead of unknown loadings and specific variations shall be used their estimations. Henceforth, by means the weighted least squares method of Bartlett we achieve the estimate of the $i$-th line $F$ as:

$$
F_{i}=\left(\hat{\Lambda}^{\prime} \times \hat{\Psi}^{-1} \times \hat{\Lambda}\right)^{-1} \times \hat{\Lambda}^{\prime} \times \hat{\Psi}^{-1} \times X_{i}^{\prime} .
$$

As result of the fact that the $F$ estimates follow the rotated solution, the $i$-th line estimate of the factor component score acquired as a result of multiplication U. $F^{1}$ and the $U$ matrix of the $m$ order, meeting the condition of $U . U^{\prime}=I$. In order to acquire to factor scores with the physics-oriented meaning, the APCS matrix is calculated, in the way that the reference value of $F_{0}$ is calculated: 


$$
F_{0}=\left(\hat{\Lambda}^{\prime} \times \hat{\Psi}^{-1} \times \hat{\Lambda}\right)^{-1} \times \hat{\Lambda}^{\prime} \times \hat{\Psi}^{-1} \times X_{0}
$$

where:

$$
\left(X_{0}\right)_{j}=-\frac{\bar{x}_{j}}{s_{j}},
$$

$\bar{X}_{J} \quad$ sample average of i-value,

$\mathrm{s}_{j} \quad$ sample standard deviation of $j$-value,

which is subtracted from the calculated $F$ matrix following the relation:

$$
\text { APCS }=F-F_{0} \text {. }
$$

By means of utilization of Multiple Regression Analysis, where PM is a dependent variable and APCS are independent variables, one can ascertain the contributions of separately-identified sources. These are added up, while being summarized, as of the determined regression coefficients by means of their multiplication using the mean value of APCS for each common factor as an absolute contribution, which is out of the total concentration of PM re-calculated and transferred into the percentile contribution of given sources [17].

As a contributing factor to the analysis of sources creating the particulate matter, there were concentrations of metals established within the fraction of $\mathrm{PM}_{10}$ used as well as the very concentrations of particulate matter of $\mathrm{PM}_{10}$. A partial sample from the data matrix $18 \times 108$ is quoted within the Table 5, where concentrations of metals are in the $\mathrm{ng} / \mathrm{m}^{3}$ units and concentrations of $\mathrm{PM}_{10}$

\begin{tabular}{|c|c|c|c|c|c|c|c|c|c|c|c|c|c|c|c|c|c|c|}
\hline & $\mathrm{Na}$ & $\mathbf{M g}$ & Al & $\mathrm{Ca}$ & $\mathrm{Cu}$ & Sb & $\mathrm{Ba}$ & $\mathrm{Pb}$ & Cd & $\mathrm{Cr}$ & As & Mo & v & Mn & $\mathrm{Fe}$ & $\mathrm{Ni}$ & $Z n$ & $\mathrm{PM}_{10}$ \\
\hline 1 & 154.0 & 514.8 & 261.9 & 1686.0 & 39.3 & 5.8 & 23.3 & 23.5 & 0.9 & 2.8 & 1.6 & 1.2 & 0.7 & 20.1 & 931.9 & 1.2 & 135.0 & 52.6 \\
\hline 2 & 74.6 & 542.3 & 139.6 & 1395.7 & 11.2 & 2.3 & 7.5 & 13.3 & 0.5 & 1.3 & 1.7 & 0.4 & 0.4 & 7.9 & 284.0 & 0.3 & 108.8 & 48.5 \\
\hline 3 & 124.8 & 483.2 & 291.2 & 1700.6 & 31.8 & 4.6 & 19.0 & 9.0 & 0.3 & 1.7 & 1.1 & 1.0 & 0.8 & 15.1 & 691.2 & 0.8 & 93.8 & 55.1 \\
\hline 4 & 250.7 & 668.1 & 124.6 & 1151.0 & 11.1 & 2.9 & 8.0 & 3.9 & 0.1 & 1.1 & 0.3 & 1.0 & 0.3 & 5.4 & 196.9 & 0.1 & 78.1 & 31.2 \\
\hline 5 & 445.5 & 490.6 & 157.1 & 1128.5 & 18.0 & 2.3 & 10.6 & 2.9 & 0.1 & 1.0 & 0.2 & 0.6 & 0.3 & 6.8 & 371.3 & 0.5 & 61.1 & 27.5 \\
\hline : & $\vdots$ & $\vdots$ & $\vdots$ & $\vdots$ & $\vdots$ & $\vdots$ & $\vdots$ & $\vdots$ & $\vdots$ & $\vdots$ & $\vdots$ & $\vdots$ & $\vdots$ & $\vdots$ & $\vdots$ & $\vdots$ & $\vdots$ & $\vdots$ \\
\hline 106 & 48.5 & 60.6 & 41.1 & 344.0 & 14.9 & 2.0 & 5.1 & 3.9 & 0.1 & 1.1 & 1.1 & 0.3 & 0.6 & 7.0 & 408.0 & 0.1 & 16.0 & 18.1 \\
\hline 107 & 96.8 & 113.8 & 42.7 & 310.6 & 12.6 & 1.9 & 6.2 & 3.0 & 0.1 & 0.1 & 0.4 & 0.4 & 0.1 & 4.5 & 267.9 & 0.2 & 18.6 & 14.5 \\
\hline 108 & 27.1 & 20.9 & 24.2 & 188.4 & 5.2 & 1.7 & 3.3 & 3.3 & 0.1 & 1.9 & 0.4 & 0.2 & 0.1 & 9.3 & 214.6 & 0.1 & 29.3 & 24.5 \\
\hline
\end{tabular}
in $\mu \mathrm{g} / \mathrm{m}^{3}$ units.

Table 5: Part of data matrix observed concentrations of metals and $\mathrm{PM}_{10}$ [14].

In order to establish the appropriateness of the factor analysis adoption the criteria of KMO and MSA were calculated. In accordance with them the adoption of factor/factorial analysis is substantiated. The results of statistical tests for the appropriateness of factor analysis adoption:

$\mathrm{KMO}$ criterion: $\mathrm{KMO}=0.88-$ a very good correlation of characters .

Bartlett Sphericity Test: Criterion $=2501.7$, Degrees of variance $=153, P=0.000$.

The calculated significance level of $P$ is significantly lower than the given level of $\alpha=0.05$, that is why the PCA may be applied on this set of data. 
Table 6: MSA criterion [14].

\begin{tabular}{|c|c|c|c|c|c|c|c|c|c|c|c|c|c|c|c|c|c|}
\hline $\mathbf{N a}$ & $\mathbf{M g}$ & $\mathbf{A l}$ & $\mathbf{C a}$ & $\mathbf{C u}$ & $\mathbf{S b}$ & $\mathbf{B a}$ & $\mathbf{P b}$ & $\mathbf{C d}$ & $\mathbf{C r}$ & $\mathbf{A s}$ & $\mathbf{M o}$ & $\mathbf{V}$ & $\mathbf{M n}$ & $\mathbf{F e}$ & $\mathbf{N i}$ & $\mathbf{Z n}$ & $\mathbf{P M}_{10}$ \\
\hline 0.86 & 0.73 & 0.83 & 0.81 & 0.91 & 0.95 & 0.93 & 0.87 & 0.90 & 0.89 & 0.91 & 0.88 & 0.86 & 0.88 & 0.92 & 0.88 & 0.91 & 0.83 \\
\hline
\end{tabular}

Particular characters are predicated with the other ones very precisely (Table 6).

Whereas, at the factor analysis it is deemed to be necessary to specify the number of factors and then the calculation may be run, during the first step the analysis of principal components was performed. As a result of which we could conclude the possible number of principal components which, to a sufficient measure, specify the variability, variety of characters. As observed in the Fig. 4 we are able to select the number of principal components 3. There are eigenvalues for each principal components in the Table 7 . The three principal components define $79.66 \%$ of the total variability of the original characters.

Table 7: Eigenvalues of correlation matrix chart [14].

\begin{tabular}{|c|c|c|c|c|}
\hline $\begin{array}{c}\text { Number } \\
\text { of PC }\end{array}$ & Eigenvalue & $\begin{array}{c}\text { \% of } \\
\text { total } \\
\text { variance }\end{array}$ & $\begin{array}{c}\text { Cumulative } \\
\text { eigenvalue }\end{array}$ & $\begin{array}{c}\text { Cumulative } \\
\%\end{array}$ \\
\hline $\mathbf{1}$ & $\mathbf{1 0 . 9 6}$ & $\mathbf{6 0 . 8 7}$ & $\mathbf{1 0 . 9 6}$ & $\mathbf{6 0 . 8 7}$ \\
\hline $\mathbf{2}$ & $\mathbf{2 . 1 9}$ & $\mathbf{1 2 . 1 6}$ & $\mathbf{1 3 . 1 5}$ & $\mathbf{7 3 . 0 4}$ \\
\hline $\mathbf{3}$ & $\mathbf{1 . 1 9}$ & $\mathbf{6 . 6 3}$ & $\mathbf{1 4 . 3 4}$ & $\mathbf{7 9 . 6 6}$ \\
\hline $\mathbf{4}$ & 0.77 & 4.29 & 15.11 & 83.95 \\
\hline $\mathbf{5}$ & 0.63 & 3.52 & 15.74 & 87.47 \\
\hline $\mathbf{6}$ & 0.50 & 2.79 & 16.25 & 90.26 \\
\hline $\mathbf{7}$ & 0.48 & 2.66 & 16.73 & 92.92 \\
\hline $\mathbf{8}$ & 0.28 & 1.54 & 17.00 & 94.47 \\
\hline $\mathbf{9}$ & 0.18 & 1.01 & 17.19 & 95.48 \\
\hline $\mathbf{1 0}$ & 0.16 & 0.89 & 17.35 & 96.37 \\
\hline $\mathbf{1 1}$ & 0.15 & 0.83 & 17.50 & 97.20 \\
\hline $\mathbf{1 2}$ & 0.14 & 0.76 & 17.63 & 97.96 \\
\hline $\mathbf{1 3}$ & 0.10 & 0.58 & 17.74 & 98.54 \\
\hline $\mathbf{1 4}$ & 0.09 & 0.51 & 17.83 & 99.05 \\
\hline $\mathbf{1 5}$ & 0.07 & 0.37 & 17.90 & 99.42 \\
\hline $\mathbf{1 6}$ & 0.05 & 0.25 & 17.94 & 99.67 \\
\hline $\mathbf{1 7}$ & 0.03 & 0.18 & 17.97 & 99.85 \\
\hline $\mathbf{1 8}$ & 0.03 & 0.15 & 18.00 & 100.00 \\
\hline
\end{tabular}

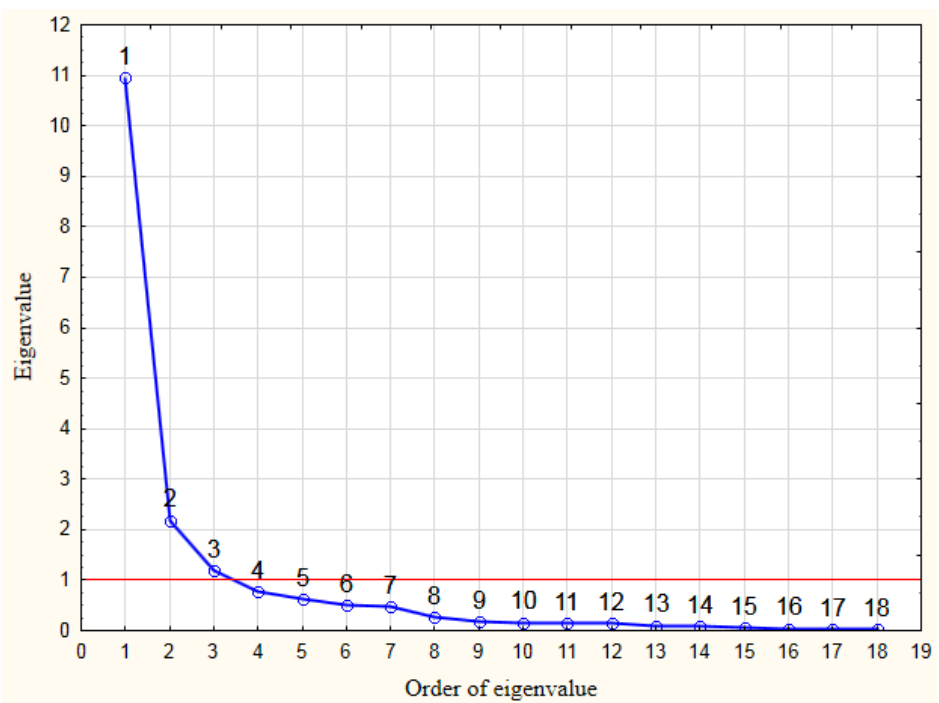

Fig. 4: Graph of eigenvalues correlation matrix - PCA [14]. 

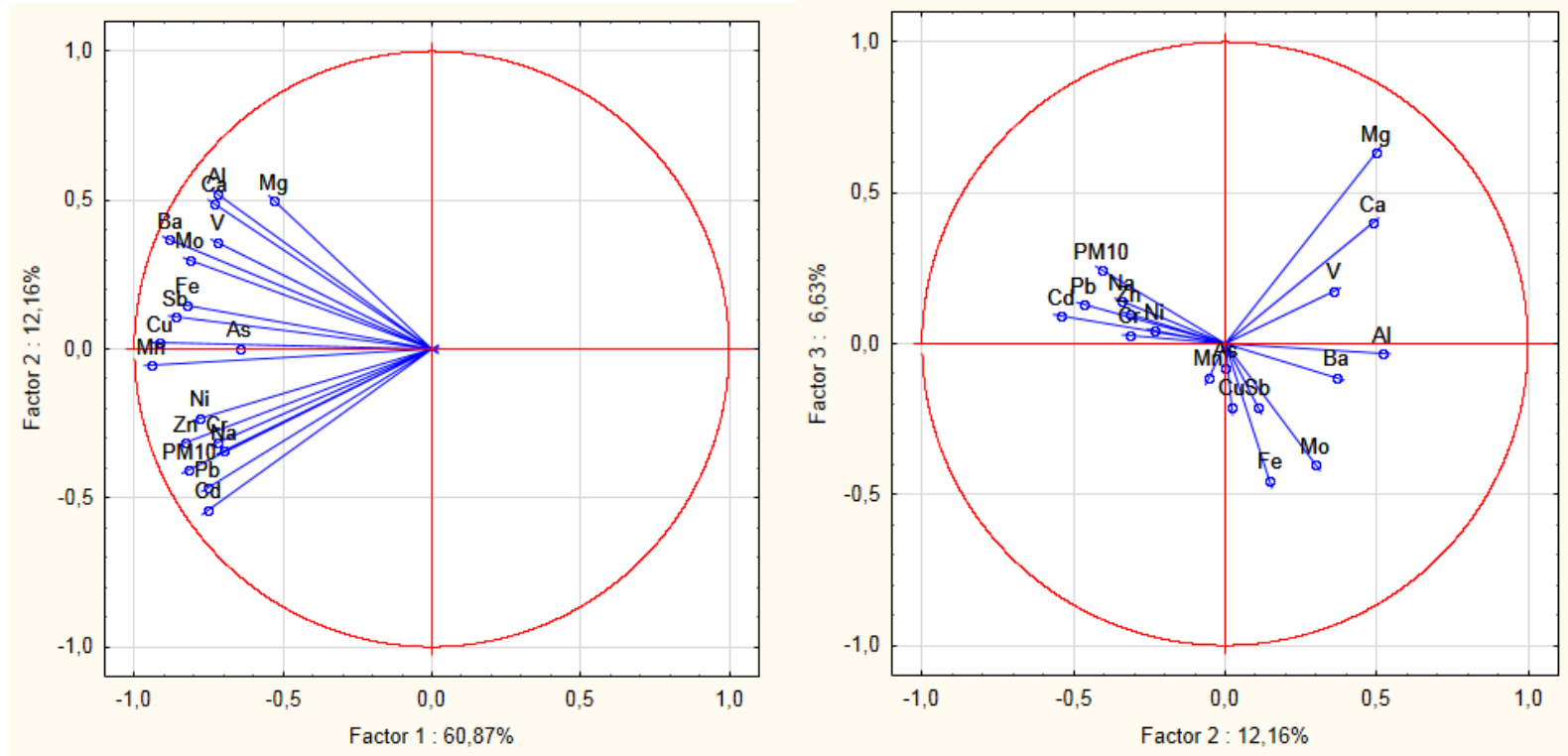

Fig. 5: Projection of the variables in the factor plane $(1 \times 2)$ up and $(2 \times 3)$ down [14].

Some variables create clusters which contribute to some of the main components building them up („Factor 1, 2, 3“) - without rotation of factors (Fig. 5). A short distance between the two signs means a strong correlation. The diverse order of signs in the factor level signifies a negative correlation of the variables. In case the signs do not correlate with each other at all, their vectors form an angle of $90^{\circ}$ degrees.

There were 3 factors selected for the factor analysis. The used model of factors rotation was Varimax. In the Table 8 the factor loadings of characters are quoted in relation to factors. They may be explained as the correlation between the factors and characters. They represent the most important unit of information the interpretation of factors is based on.

Table 8: Factor loads - FA [14].

\begin{tabular}{|c|c|c|c|}
\hline Variable & Factor 1 & Factor 2 & Factor 3 \\
\hline $\mathbf{N a}$ & $\mathbf{0 . 7 3}$ & 0.24 & 0.17 \\
\hline $\mathbf{M g}$ & 0.13 & 0.10 & $\mathbf{0 . 9 5}$ \\
\hline $\mathbf{A l}$ & 0.08 & 0.68 & 0.56 \\
\hline $\mathbf{C a}$ & 0.21 & 0.39 & $\mathbf{0 . 8 6}$ \\
\hline $\mathbf{C u}$ & 0.52 & $\mathbf{0 . 7 4}$ & 0.23 \\
\hline $\mathbf{S b}$ & 0.43 & $\mathbf{0 . 7 4}$ & 0.26 \\
\hline $\mathbf{B a}$ & 0.27 & $\mathbf{0 . 7 8}$ & 0.49 \\
\hline $\mathbf{P b}$ & $\mathbf{0 . 8 6}$ & 0.24 & 0.12 \\
\hline $\mathbf{C d}$ & $\mathbf{0 . 9 0}$ & 0.24 & 0.05 \\
\hline $\mathbf{C r}$ & $\mathbf{0 . 7 0}$ & 0.34 & 0.12 \\
\hline $\mathbf{A s}$ & 0.40 & 0.48 & 0.20 \\
\hline $\mathbf{M o}$ & 0.21 & $\mathbf{0 . 9 1}$ & 0.21 \\
\hline $\mathbf{V}$ & 0.24 & 0.48 & 0.62 \\
\hline $\mathbf{M n}$ & 0.62 & 0.67 & 0.26 \\
\hline $\mathbf{F e}$ & 0.31 & $\mathbf{0 . 8 9}$ & 0.09 \\
\hline $\mathbf{N i}$ & 0.68 & 0.40 & 0.20 \\
\hline $\mathbf{Z n}$ & $\mathbf{0 . 7 9}$ & 0.36 & 0.22 \\
\hline $\mathbf{P M}$ & $\mathbf{0 . 8 8}$ & 0.23 & 0.26 \\
\hline \multicolumn{2}{|c}{} & &
\end{tabular}




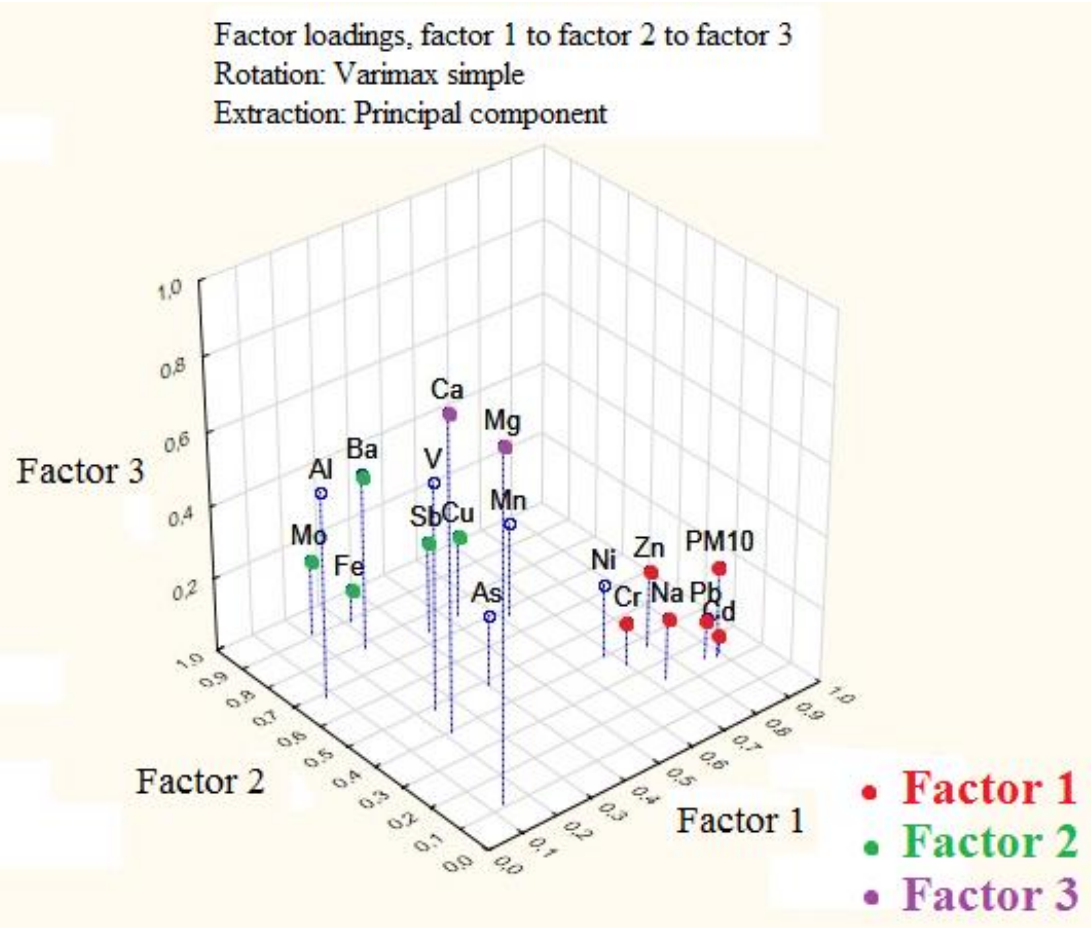

Fig. 6: Factor loads, factor 1 to factor 2 to factor 3 [14].

Each factor is contributed by several elements (characters) (Table 8, Fig. 6). As the most decisive factor of loads the values close to or greater than 0.7 were selected. Based on the representation and presence of elements in particular, selected factors, the following factors may be named:

Factor 1: $\mathrm{Na}, \mathrm{Pb}, \mathrm{Cd}, \mathrm{Zn}, \mathrm{Cr}, \mathrm{PM}_{10}$.

Factor 2: $\mathrm{Cu}, \mathrm{Sb}, \mathrm{Ba}, \mathrm{Mo}, \mathrm{Fe}$.

Factor 3: $\mathrm{Mg}, \mathrm{Ca}$.

\section{APCS Results}

All the variables (factors) are within the model to be understood as significant ones $\left(^{* \star *}\right)$ and to a greater extent contribute to $\mathrm{PM}_{10}$ concentrations (Table 9).

Determination coefficient describes a share of the overall distribution, which may be clarified by means of a linear relation. In this case it bears the value of $R^{2}=0.92$, which means that the linear relation clarifies a sufficient part of the overall variability.

The significance level is very small $\mathrm{P}<2.2 \mathrm{e}^{-16}$, the adoption of a given model thence sufficiently significant.

Table 9: Results as of the multilayer regression analysis $\left(\mathrm{PM}_{10}\right.$ is a dependant variable, independent variables absolute score for specific factors) for daily and nightly sampling [14].

\begin{tabular}{|c|c|c|c|c|c|}
\hline Variable & Parameter & $\begin{array}{c}\text { Std. } \\
\text { Error }\end{array}$ & t-value & $\mathbf{p}$ & $\begin{array}{c}\text { Significance } \\
\text { of the } \\
\text { variable }\end{array}$ \\
\hline (Unresolved) & 9.40 & 2.13 & 4.42 & $2.39 \mathrm{e}^{-5}$ & ${ }^{-5 * *}$ \\
\hline APCSFactor1 & 33.78 & 1.00 & 32.76 & $<2 \mathrm{e}^{-16}$ & ${ }^{* * *}$ \\
\hline APCSFactor2 & 6.91 & 1.00 & 6.91 & $3.98 \mathrm{e}^{-10}$ & ${ }^{* * *}$ \\
\hline APCSFactor3 & 9.79 & 1.01 & 9.68 & $3.49 \mathrm{e}^{-16}$ & ${ }^{* * *}$ \\
\hline
\end{tabular}


Table 10: Absolute contributions of factors towards the mean concentration of $\mathrm{PM}_{10}\left[\mu \mathrm{gg} / \mathrm{m}^{3}\right][14]$.

\begin{tabular}{|c|c|c|c|c|}
\hline & Unresolved & APCS1 & APCS2 & APCS3 \\
\hline APCS & 9.40 & 29.66 & 9.48 & 8.00 \\
\hline
\end{tabular}

Table 11: Percentile contributions of factors towards the mean concentration of $\mathrm{PM}_{10}$ [\%] [14].

\begin{tabular}{|c|c|c|c|c|}
\hline & Unresolved & APCS1 & APCS2 & APCS3 \\
\hline APCS & 16.62 & 52.45 & 16.77 & 14.16 \\
\hline
\end{tabular}

There are absolute contributions and percentile contributions of factors towards the mean concentration of $\mathrm{PM}_{10}$ in the Table 10 and Table 11. Average absolute contributions and average percentile contributions of factors relate to average concentration of $\mathrm{PM}_{10} 56,55 \mu \mathrm{gg} / \mathrm{m}^{3}$ from all analysed data [14].

\section{Discussion as of the achieved results}

The results of the regression analysis comprised in order to determine the influence of the ambient meteorological conditions on the concentrations of PM do include several establishments. The most significant impact on the fraction of $\mathrm{PM}_{1}$ (ultrafine fraction) was possessed by the ambient air temperature, which correlated with that fraction in a rather negative manner. The most significant impact on the fraction of $\mathrm{PM}_{2,5}$ (fine fractions) was equally possessed by the ambient air temperature, impacting on the fraction of $\mathrm{PM}_{2,5-10}$ (entirely coarse fraction segregated) was possessed by the ambient air humidity. The overall fraction of $\mathrm{PM}_{10}$ was impacted to the most significant degree, repeatedly by the ambient air temperature, which is caused by the presence of fine fraction of $\mathrm{PM}_{2,5}$ in this overall fraction amounting to $65-90 \%$. Considering the temperature having the great impact on the concentrations of PM is caused by various facts. With lower temperatures the dissipation conditions do worsen - the currents in the ambient air, which results in the continuous and long-term stagnation in one place. Low temperatures cause condensation of water vapours, steam, several gaseous pollutants, which in the long run creates the creation of very fine aerosol [18].

In order to identify the origin of the particulate matter at the aforementioned monitoring station, the usage of factor analysis proved as the appropriate one. As resulted from the factor analysis, the original dataset may be explained using several factors. The three factors explain $79.66 \%$ of the total variability of the original characters. Naming these factors is enabled based on the characters, which specify unique factors. This is, at the same time, conditioned by a supposition of the fact where separate elements - heavy metals - may originate from. The survey on the origin may be drawn from the former research surveys performed by various authors. In the monitored station, the primary cause of particulate matter originates as a consequence of the vehicular traffic. We follow the supposition that the observed metals are traced to specific automotive components and the road surface itself (Table 1). Based on the results of factor analysis and the supposed sources, the factors of 1 and 3 were named, designated in the following manner: Factor 1 - Tyre wear and tear and gritting materials. Factor 2 - Brake pads lining tear and wear, brake pads, car components and combustion of propulsive, propulsion fuels. Factor 3 - Road pavement wear - aggregate, road tar binders and road dust.

The results of statistical analyses being quoted in this very contribution do present the results as of the performed monitoring, as from the one place for the duration of three consecutive years in the urban, built-up area of the city, in close observance of the 108 samples of contaminated filters with particulates.

Using the APCS method while supported by adoption of the input data the following may be implicated: the contribution of the tyre tear and wear and gritting materials to the $\mathrm{PM}_{10}$ formation by $52.45 \%$, brake pads lining tear and wear, brake pads, car components and combustion or propulsive, propulsion fuels by $16.77 \%$, road pavement wear - aggregate, road tar binders and road dust by $14.16 \%$ and unresolved part by $16.62 \%$.

A detailed specification of contribution towards particular sources of $\mathrm{PM}_{10}$ formation may be narrowly specified by a number of chemical elements and compounds, based on which statistical analyses are performed. 
Similar results were achieved in the Czech Republic [19], England [20], authors of the following study [18] do happen to quote that re-suspension may contribute up to $60 \%$ towards the creation of aerosol fraction of $\mathrm{PM}_{10}$. As of TSP the share of emissions resulting from the wear may be even higher that the share of burnt emissions [21]. Each of the asphalt mixtures used for road pavement [22] is a specific one, when relating to their composition - asphalt type, amount of asphalt, kind of aggregate, various lines of granularity and fraction in the composites. With regard to the materials used, there are various samples created observing similar surface structures [23], which can in the long run influence the abrasion of these road pavements [24].

\section{Acknowledgement}

The paper originated thanks to being supported by means of a grant for the scientific research task VEGA 1/0508/2011 entitled Overall characteristics and chemical composition of particulates as created by the vehicular traffic.

This contribution is the result of the project implementation: "Promotion \& Enhancement of Transportation Research Centre" (ITMS: 26220220160) supported by the Research \& Development Operational Programme funded by the ERDF.

\section{References}

[1] Act of the National Council of the Slovak Republic No. 137/2010 on the Air and Atmosphere.

[2] Public Notice, Decree No. 360/2010 of the Ministry of Agriculture and the Environment and the Regional Development of the Slovak Republic on the quality of air.

[3] DURZA, O. 2003. The Utilization of Soil Magnetometry in the Environmental Geochemistry of Heavy Metals (in Slovak). In Acta Geologica Universitatis Comenianae. 2003, Nr. 58, p. 29-55.

[4] STN EN 12341: 2001 Air quality. Determination of $\mathrm{PM}_{10}$ fraction of suspended particulate matter. Reference Method and Field test procedure to demonstrate reference equivalence of measurement methods.

[5] STN EN 14907: 2005 Air quality. Ambient Air quality. Standard gravimetric measurement method for the determination of the $\mathrm{PM}_{2.5}$ mass fraction of suspended particulate.

[6] STN EN 14902: 2005 Ambient air quality. Standard method for the measurement of $\mathrm{Pb}, \mathrm{Cd}$, As and $\mathrm{Ni}$ in the $\mathrm{PM}_{10}$ fraction of suspended particulate matter.

[7] WEINBRUCH, S. - EBERT, M. 2004. Source Apportionment of Atmospheric Aerosols Based on Electron Microscopy, Technical University of Darmstadt, 2004.

[8] McCULLUM, K. - KINDZIERSKI, W. 2001. Analysis of Particulate Matter Origin in Ambient Air at High Level. Department of Civil and Environmental Engineering, University of Alberta, Edmonton, Alberta. 2001.

[9] GATARI, M. J. - BOMAN, J. - WAGNER, A. - JANHALL, S. - ISAKSON, J. 2006. Assessment of Inorganic Content of $\mathrm{PM}_{2.5}$ Particles Sampled in a Rural Area North East of Hanoi. In Science of the Total Environment 368 [online]. 2006, vol. 368, issue 2-3, p. 675 - 685 [cit. 21. 02. 2014]. Available at: http://www.sciencedirect.com/science/article/pii/S0048969706002920. ISSN 00489697.

[10] VOJTESEK, M. - MIKUSKA, P. - VECERA, Z. 2009. Presence, Sources and Classification of metals present in the Air (in Czech). In Chemical Letters 103. ISSN 1213-7103, 2009.

[11]THORPE, A. - HARRISON, R. M. 2008. Sources and Properties of Non-exhaust Particulate Matter from Road Traffic: A review. In Science of Total Environment [online]. 2008, vol. 400, issue 1-3, p. 270-282 [cit. 21. 02. 2014]. Available at:

http://www.sciencedirect.com/science/article/pii/S004896970800658X. ISSN 0048-9697.

[12] PANT, P. - HARRISON, R. M. 2013. Estimation of the contribution of road traffic emissions to particulate matter concentrations from field measurements: A review. In Atmospheric Environment [online]. 2013, vol. 77, p. 78 - 97 [cit. 21. 02. 2014]. Available at: http://www.sciencedirect.com/science/article/pii/S1352231013002732. ISSN 1352-2310.

[13]BUJDOS, M. - HAGAROVA, I. - MATUS, P. - CANECKA, L. - KUBOVA, J.: Optimization of Determination of Platinum Group Elements in Airborne Particulate Matter by Inductively Coupled Plasma Mass Spectrometry. In Acta Chimica Slovenica. ISSN 1318-0207, 2012, vol. 59, No. 1, pp. 124-128. 
[14]JANDACKA, D.: Road Transport Impact on the Occurrence of Particulates: Dissertation thesis. Zilina: University of Zilina, 2012. $134 \mathrm{p}$.

[15]MELOUN, M. - MILITKY, J.: Compendium of statistical data processing (in Czech). Prague: Academia, 2006, 982 p. ISBN 80-200-1396-2.

[16]MELOUN, M. - MILITKY, J.: Statistical Analysis of Experimental Data (in Czech). Prague: Academia, 2004. 953 p. ISBN 80-200-1254-0.

[17] HUZLIK, J. - LICBINSKY, R. - MIKUSKA, P. 2011. Identification of Re-suspended Particle Matter Particles Sources by Statistical Methods. In $12^{\text {th }}$ Annual Conference of the Czech Aerosol Society: proceedings. Cejkovice: 2011, ISBN 978-80-86186-31-3, p. 69-74.

[18] CAPLAIN, I. - CAZIER, F. - NOUALI, H. - MERCIER, A. - DECHAUX, J. C. - NOLLET, V. JOUMARD, R. - ANDRE, J. M. - VIDON, R. 2006. Emissions of unregulated pollutants from European gasoline and diesel passenger cars. In Atmospheric Environment [online]. 2006, vol. 40, issue 31, p. 5954-5966 [cit. 21. 02. 2014]. Available at: http://www.sciencedirect.com/science/article/pii/S1352231006000525. ISSN 1352-2310.

[19] VOJTESEK, M. - MIKUSKA, P. - LICBINSKY, R. - ADAMEC, V. - KRUMAL, K. 2010. Seasonal variations of concentrations of metals in atmospheric aerosol and road dust in Brno and Ostrava (in Czech), In $11^{\text {th }}$ Annual Conference of the Czech Aerosol Society: proceedings. Prague: 2010, ISBN 978-80-86186-25-2.

[20] ALLEN, A. G. - NEMITZ, E. - SHI, J. P. - HARRISON, R. M. - GREENWOOD, J. C. 2001. Size distributions of trace metals in atmospheric aerosols in the United Kingdom. In Atmospheric Environment [online]. 2001, vol. 35, issue 27, p. 4581-4591[cit. 21. 02. 2014]. Available at: http://www.sciencedirect.com/science/article/pii/S135223100100190X. ISSN 1352-2310.

[21] YLI-TUOMI, T. - AARMIO, P. - PIRJOLA, L. - MAHELA, T. - HILLAMO, T. - JANTUNEN, M. 2005. Emitions of fine particles, NOx and $\mathrm{CO}$ from on-road vehicles in Finland. In Atmospheric environment [online]. 2005, vol. 39, issue 35. p. 6696-6706 [cit. 21. 02. 2014]. Available at: http://www.sciencedirect.com/science/article/pii/S1352231005006849.ISSN 1352-2310.

[22]DECKY, M. - GAVULOVA, A. - PUTIRKA, D. - PITONAK, M. - VANGEL, J. - ZGUTOVA, K. 2010. Designing and Calculating Asphalt-paved Carriageways (in Slovak). University of Zilina, 2010. 300 p. ISBN 978-80-970388-0-9.

[23]KOVAC, M. - REMISOVA, E. - DECKY, M. - DURCANSKA, D. - CELKO, J. 2012. Diagnostics of pavement serviceability parameters (in Slovak). $1^{\text {st }}$ edition. Žilina: University of Zilina, 2012. 256 p. ISBN 978-80-554-0568-1.

[24]JANDACKA, D. - KOVAC, M. - DURCANSKA, D. - DECKY, M. 2013. Particulate matter produced by different road pavement asphalt mixtures (in Slovak). In Air protection 2013 Conference: proceedings. Štrbské pleso: Kongres STUDIO, spol. s r. 0., 2013. ISBN 978-80-89565-11-5. p. 9195. 